\title{
Rule-governed missing information in spoken word recognition: Schwa vowel deletion
}

\author{
PAUL C. LOCASTO and CYNTHIA M. CONNINE \\ State University of New York, Binghamton, New York
}

\begin{abstract}
Vowel deletion is a phonological process in which an unstressed/ə/ (schwa) vowel is deleted during pronunciation. In Experiment 1, vowel-deleted and vowel-reduced versions of two- and three-syllable words rated for pronunciation acceptability showed reduced acceptability for deleted vowel versions with a greater decrement for two-syllable words. Experiments 2 and 3 used vowel-intact and voweldeleted productions preceded by themselves (repetition prime), their alternative production (variant prime), or a control (unrelated) prime. Lexical decisions to three-syllablevowel-intact and vowel-deleted targets, as well as to two-syllable vowel-intact targets, showed greaterpriming in the repetition conditions than in the variant conditions. Two-syllable vowel-deleted targets, however, showed comparable repetition and variant priming. The results are discussed in terms of lexical activation and representation of phonological variants. A model is offered in which activation based on similarity triggers utilization of phonological inferences only when required for successful recognition.
\end{abstract}

To recognize spoken words, a pervasive obstacle must be overcome: variability in the acoustic stimulus. Variability can occur in the form of misarticulations, environmental noise masking acoustic segments, phonological processes acting on adjacent phonemes, as well as dialectic variability in word pronunciation. These factors have the potential to disrupt the mapping process between the acoustic-phonetic signal and lexical representations. The present line of research focuses on the processing of phonological variation - specifically, optional vowel deletion in English.

Previous research has suggested that spoken word recognition is quite tolerant of deviations from canonical form relying on the overall goodness of fit between the signal and a lexical representation (see Connine, 1994; Connine, Blasko, \& Titone, 1993; Connine, Titone, Deelman, \& Blasko, 1997; Ye \& Connine, 1999). However, these findings have been based almost exclusively on consonants, and some recent research suggests interesting asymmetries. Van Ooijen (1996) used a word reconstruction paradigm to directly compare processing of vowels and consonants. Participants heard "word-like" nonwords (such as eltimate) and were instructed to respond when they were able to identify a word similar to it. Van Ooijen found more word

Portions of this research were presented at the 1998 Fall Meeting of the Acoustical Society of America. The research was supported by NIDCD Grant R01 DC02134 to the second author. Additional support was provided by the Center for Cognitive and Psycholinguistic Sciences. We thank John Kingston and James McQueen for their helpful comments. We also thank Rena Paris and Amy Ringler for assisting in data collection. Address correspondence to P. C. LoCasto, Department of Psychology, State University of New York, Binghamton, NY 13902 (e-mail: plocasto@ binghamton.edu) or C. M. Connine, Department of Psychology, State University of New York, Binghamton, NY 13902 (email: connine@binghamton.edu). reconstructions formed by altering the identity of vowels, as compared with consonants, and suggested that vowels are treated as less defined, or more variable, than consonants (see also McQueen, Norris, \& Cutler, 1994).

One way to investigate this is to ask how variability in vowel information is used when mapping between the speech signal and lexical representations. We approach this question by focusing on schwa deletion, a naturally occurring, rule-governed form of variability. In linguistic analyses, schwas (/ə/, generally used to specify midcentral vowels) usually appear in weak syllables. ${ }^{1}$ Schwas may be optionally deleted: If a stressed syllable is followed by two syllables, each with less stress, the vowel immediately following the stressed syllable can be deleted (Oshika, Zue, Weeks, Neu, \& Aurbach, 1975). This deletion rule can apply to three-syllable words and reduces the word to two syllables (e.g., envelope $\rightarrow$ /Envlop/). A schwa may also be deleted in the word-initial syllable when preceded by at least one consonant and followed by a stressed syllable (e.g., police $\rightarrow /$ plis/). In the present experiments, two- and three-syllable words containing a schwa were pronounced with (reduced form) or without (vowel deleted) a vowel. In both two- and three-syllable words, vowel deletion presents challenges for word recognition.

There are at least three general approaches to how phonological variations can be accommodated during word recognition. One possibility is that their inherent variability translates into a limited role for vowels in lexical representations. The strictest representational approach would assume that variable vowel information is not represented at all or is represented in a way that reflects less stringent reliance on it. If there is reduced reliance on vowel information during recognition, the effects should be most visible under extreme instances of variation, such as vowel deletion. A second account assumes that schwa 
deletion environments utilize mechanisms that capitalize on its predictable, rule-governed nature. There are at least two ways in which this systematicity may be exploited. One way is that processing in a licensed environment compensates for the lack of complete overlap between input and representation. In an extreme view, a prelexical computation serves to restore the missing vowel before lexical contact occurs. Such a computation on phonological variants would result in functionally comparable effects on lexical activation for alternative pronunciations. This view is most consistent with claims concerning processing of phonological variants, such as those caused by place assimilation (see Gaskell \& Marslen-Wilson, 1996, 1998). Gaskell and Marslen-Wilson (1996) found that potential place assimilation variants are treated as their base forms (LEAM and LEAN are equivalent primes for LEAN) in the absence of a following context to license the assimilation variant. A comparable mechanism for vowel deleted variants would treat all potential voweldeleted variants identically.

An alternative assumes that use of phonological knowledge is targeted for words only when relevant-that is, only for words experienced by the listener in their variant form. On this view, access to and utilization of phonological knowledge requires activation of a lexical representation. This account raises some interesting possibilities as to how this knowledge is coordinated with other lexical processes, such as activation as a function of overlap with the input. If phonological knowledge is available when processing a variant only after a word has been recognized, it could serve only a limited role in confirming an already recognized word. Alternatively, phonological knowledge may be used to fill in missing or partial information in the same way that lexical knowledge can augment ambiguous (Connine \& Clifton, 1987) or lexically consistent segmental hypotheses (Connine et al., 1997). Thus, functional effects may become evident only when activation of a lexical representation is partial and insufficient for recognition. On this view, the use of phonological knowledge in recognizing variants is neither prelexical nor postlexical. Rather, knowledge of rule-governed variation serves to augment activation of lexical hypotheses when signal conditions and/or the state of the lexicon results in insufficient activation for recognition. This is consistent with findings in processing place assimilation variants. Gaskell and Marslen-Wilson (1998) found effects of phonological inference on the perception of nonwords, although the inference effects interacted with lexical access.

In order to examine these possibilities, we investigated the effects of vowel deletion on spoken word recognition in two complementary ways. In the first experiment, vowelreduced and vowel-deleted versions of words were presented to listeners to rate for acceptability. The goal was to obtain a subjective measure of the acceptibility of vowelreduced and vowel-deleted variant productions (see Connine, Mullennix, Shernoff, \& Yelen, 1990, and Gernsbacher, 1984, for a similar use of subjective ratings for word frequency). Acceptability ratings provide one avenue by which to distinguish among the various alternatives described above. If the lexical representations of either twoor three-syllable words do not contain (or there is reduced reliance on) the optional vowel, vowel-deleted pronunciations should result in comparable (or higher) ratings, as compared with their vowel-intact counterparts. If the missing vowel is restored prelexically or if multiple representations exist in order to accommodate the vowel-deleted variants, then once again, no difference in acceptability should be found. These hypotheses are similar in that they predict comparable ratings across variants for two- and threesyllable words.

However, if processing schwa deletion relies on phonological knowledge associated with individual words that augments lexical activation of the canonical representation, differences across two- and three-syllable words should be observed. In general, vowel-deleted stimuli should be rated less acceptable than their vowel-intact counterparts. In particular, this reduction in acceptability should be smaller for three-syllable words than for two-syllable words. Three-syllable words provide greater redundancy in specifying lexical identity, even in their vowel-deleted versions. These words should therefore provide a more effective match to a lexical representation, along with less possible competition from similar sounding neighbors. Thus, hearing a vowel-deleted version of a three-syllable word is less detrimental than hearing a vowel-deleted version of a two-syllable word.

Experiments 2 and 3 used form priming to investigate on-line processing of vowel-deleted and vowel-intact variants. In form priming, words overlapping in form (e.g., dent/tent) are presented in prime-target pairs. Reaction time as a function of prime type is used to infer to what degree a prime activates a lexical representation (Slowiaczek \& Hamburger, 1992; Zwitserlood, 1996). The task was extended here to investigate the processing of phonological variants. A second goal was to assess the efficacy of the acceptibility ratings, relative to an on-line task.

\section{EXPERIMENT 1}

\section{Method}

\section{Participants}

A group of 50 undergraduates from Binghamton University participated in the experiment to fulfill a course requirement.

\section{Materials and Design}

A set of 72 three-syllable words with a medial weak vowel (Appendix A) and a set of 24 two-syllable words with an initial weak vowel (Appendix B) were selected. Two versions of each word were recorded, one with the schwa (vowel-reduced variant) and one (voweldeleted) with an intentional complete deletion of the medial (threesyllable words) or initial (two-syllable words) vowel. All the stimuli were recorded in a sound-dampened room and digitized at $10 \mathrm{kHz}$ (12bit resolution) and low-pass filtered at $4.8 \mathrm{kHz}$. Inaudible timing marks were placed at the onset of the items to trigger timing (necessary for Experiments 2 and 3). Separate stimulus lists were made for each item list. For each list, the stimuli were counterbalanced to include the same number of reduced and deleted targets, as well as only one version (either reduced or deleted) of each item. List presentation 
order was counterbalanced across participants. Prepared rating sheets were given to the participants to record their responses (described below).

\section{Procedure}

The participants were run individually or in groups of two in a sound-dampened room. All the stimuli were presented binaurally over headphones (Sennheiser HD-250 II). Instructions directed the participants to indicate whether the stimulus they heard was an acceptable production of a word they knew (circle yes or no on the response sheet). If they answered yes, the participants were to write the word they heard on a line next to their yes response. They then rated the production's acceptability on the rating scale. The participants rated the production from 1 (barely acceptable) to 10 (very acceptable), with intermediate ratings from 2 to 9 (with 5 labeled as $a c$ ceptable). If they had circled no, the participants were instructed that, if the stimulus "reminded" them of a word, they were to write that word on the line next to their no response. Upon completion of rating a word, the participants pressed a key to hear the next stimulus. Prior to the experiment, a short practice session was presented. The entire experiment lasted approximately $40 \mathrm{~min}$.

\section{Results}

Responses were scored as correct if the stimulus was categorized as sounding like a known word and was heard as the intended word (as indicated by the word written by the participant). If the stimulus was categorized as a known word but not heard as the intended word, the response was scored as incorrect. Percentages correct, along with average acceptability ratings for correct responses, are shown in Table 1 for the two- and three-syllable words.

Analyses of variance (ANOVAs) were conducted across both participants $\left(F_{1}\right)$ and items $\left(F_{2}\right)$. Five (4 two-syllable and 1 three-syllable) items were excluded from all analyses because they were misidentified as the same wrong word ( $40 \%$ or more of the responses were the same word). Misidentifications of the remaining stimuli were few (less than $1 \%$ ) and showed no consistent pattern. A significance level of $p<.05$ was adopted for all tests.

As is clear from Table 1, three-syllable words were rated as more acceptable than two-syllable words and reduced forms were rated as more acceptable than the voweldeleted variants. However, the difference in acceptability between the vowel-reduced and the vowel-deleted forms was greater for two-syllable words ( 2.45 vs. 1.93 for twoand three-syllable words, respectively). A 2 (word length, two- or three-syllable words) $\times 2$ (variant type, reduced or deleted) ANOVA confirmed the main effects of word length $\left[F_{1}(1,49)=16.27, M S_{\mathrm{e}}=1.53 ; F_{2}(1,89)=9.82\right.$, $\left.M S_{\mathrm{e}}=1.7\right]$ and variant type $\left[F_{1}(1,49)=231, M S_{\mathrm{e}}=1.03\right.$; $\left.F_{2}(1,89)=99.84, M S_{\mathrm{e}}=1.48\right]$ and marginally confirmed their interaction $\left[F_{1}(1,49)=3.67, M S_{\mathrm{e}}=0.93, p=.06\right.$; $\left.F_{2}(1,89)=2.91, M S_{\mathrm{e}}=1.48, p=.09\right]$. Planned comparisons showed that reduced versions were rated as more acceptable than deleted versions for both two-syllable words $\left[t_{1}(49)=12.69 ; t_{2}(19)=6.28\right]$ and three-syllable words $\left[t_{1}(49)=9.46 ; t_{2}(70)=8.97\right] .{ }^{2}$ Comparisons across word lengths for vowel-deleted versions showed reduced acceptability for two-syllable words, as compared with threesyllable words $\left[5.19\right.$ vs. $\left.6.16 ; t_{1}(49)=4.46 ; t_{2}(89)=3.05\right]$. Acceptibility of reduced forms did not differ across word length.

Percentages correct also indicated differences between word length and variant type. Three-syllable items were more accurately identified than two-syllable items. In addition, vowel-reduced items were more accurately identified than vowel-deleted versions. This difference was smaller for three-syllable (7\%) than for two-syllable (14\%) pronunciations. An ANOVA showed a main effect of word length $\left[F_{1}(1,49)=11.63, M S_{\mathrm{e}}=122\right]$ that was marginal across items $\left[F_{2}(1,89)=2.50, M S_{\mathrm{e}}=450, p=.12\right]$, a main effect of variant type $\left[F_{1}(1,49)=30.76, M S_{\mathrm{e}}=184\right.$; $\left.F_{2}(1,89)=30.85, M S_{\mathrm{e}}=134\right]$ and their interaction [marginally significant across participants, $F_{1}(1,49)=3.00$, $M S_{\mathrm{e}}=172, p=.09$; significant across items, $F_{2}(1,89)=$ $\left.4.02, M S_{\mathrm{e}}=134\right]$. For both word lengths, reduced versions were correctly identified more often than deleted versions [two-syllable words, $t_{1}(49)=3.95, t_{2}(19)=3.4$; threesyllable words, $\left.t_{1}(49)=5.26, t_{2}(70)=4.12\right]$. Finally, twosyllable vowel-deleted words were identified less accurately than the three-syllable counterparts $[77 \%$ vs. $86 \%$; $t_{1}(49)=2.93, t_{2}(89)=1.99$ ]. Two- and three-syllable reduced forms did not differ (91\% vs. $93 \%$, respectively).

\section{Discussion}

The prelexical inference, multiple representation, and strict representational accounts claim that the voweldeleted pronunciations should not suffer in processing or in acceptibility ratings. However, both acceptability and accuracy were higher for reduced productions, suggesting that the schwa is lexically represented for both word types. Furthermore, both measures indicate that recognition of two-syllable vowel-deleted words was more vulnerable

Table 1

Percentages of Correct Identification and Acceptability Rating for Two- and Three-Syllable Words as a Function of Variant Type (Reduced or Vowel Deleted) in Experiment 1

\begin{tabular}{|c|c|c|c|c|c|c|c|c|}
\hline \multirow[b]{3}{*}{ Variant Type } & \multicolumn{4}{|c|}{ Two-Syllable Words } & \multicolumn{4}{|c|}{ Three-Syllable Words } \\
\hline & \multicolumn{2}{|c|}{$\begin{array}{c}\text { Percentage } \\
\text { Correct }\end{array}$} & \multicolumn{2}{|c|}{$\begin{array}{c}\text { Acceptability } \\
\text { Rating }\end{array}$} & \multicolumn{2}{|c|}{$\begin{array}{c}\text { Percentage } \\
\text { Correct }\end{array}$} & \multicolumn{2}{|c|}{$\begin{array}{l}\text { Acceptability } \\
\text { Rating }\end{array}$} \\
\hline & $M$ & $S E$ & $M$ & $S E$ & $\bar{M}$ & $S E$ & $\bar{M}$ & $S E$ \\
\hline Reduced form & 91 & 1.94 & 7.64 & 0.20 & 93 & 0.75 & 8.09 & $\overline{0.12}$ \\
\hline Vowel deleted & 77 & 2.54 & 5.19 & 0.18 & 86 & 1.20 & 6.16 & 0.16 \\
\hline
\end{tabular}

Note-For acceptability ratings, $1=$ barely acceptable, $10=$ very acceptable. 
than that of their three-syllable counterparts. This indicates that recognition of two-syllable variants might require additional support for recognition. The acceptability ratings suggest two general processing consequences of vowel deletion. First, vowel-deleted variants will not function as effectively as primes, as compared with their vowelreduced counterparts. Second, three-syllable words will have reduced processing difficulties for the vowel-deleted variants, as compared with two-syllable words.

In Experiment 2, we examined on-line processing, using a phonological priming task in which participants made lexical decisions to reduced and deleted productions when they were preceded by themselves (repetition), by their alternative production (variant), or by an unrelated (control) prime.

The representational and prelexical inference accounts, although not supported by Experiment 1, predict no difference between two- and three-syllable words. However, if as the results of Experiment 1 suggest, the schwa is represented lexically, vowel-deleted variants should show a corresponding cost in processing. This activation-based account, however, predicts processing costs for voweldeleted forms only when the target representation's activation is insufficient for recognition. For three-syllable words, if lexical redundancy is sufficient for recognizing both reduced and deleted tokens, no asymmetry across target type would be predicted. Rather, variant priming conditions should show the typical increase in reaction time, relative to the repetition condition. If phonological knowledge acts to augment the processing of vowel-deleted variants for two-syllable words, then this should be most evident for vowel-deleted targets. Specifically, the patterning of the variant priming condition should show a large benefit, assuming that the full form prime activates a lexical representation. Finally, processing in the repetition prime condition will depend on the extent to which the prime can uniquely activate the target representation.

\section{EXPERIMENT 2}

\section{Method}

\section{Participants}

A total of 97 undergraduates from Binghamton University participated in the experiment to fulfill a course requirement.

\section{Materials and Design}

Three-syllable words. The experimental items were the set of three-syllable stimuli described in Experiment 1, plus an additional set of control and filler items. Control words were matched to individual experimental stimuli to be unrelated in meaning and have a comparable stress pattern, frequency, number of syllables, and number of phonemes. Six stimuli lists were prepared, each consisting of 72 experimental items and 194 unrelated filler stimuli. The unrelated fillers (61 word-prime/word-target pairs and 133 word-prime/ nonword-target pairs) were selected to satisfy the following constraints across the list: $18 \%$ relatedness between prime and target and $50 \%$ word/nonword targets. Additional filler trials consisted of 24 vowel-deleted word-primes/nonword-targets and 24 reduced word-primes/nonword-targets . Fillers were selected to be similar in length (number of syllables and, roughly, number of phonemes), fre-
Table 2

Experimental Conditions in Experiment 2: 2 (Target Type) $\times 3$ (Prime Type)

\begin{tabular}{lllc}
\hline & \multicolumn{3}{c}{ Prime Type } \\
\cline { 2 - 4 } Target Type & Repetition & Variant & Control \\
\hline Reduced (/bəliv/) & /boliv/ & /bliv/ & salute \\
Deleted (/bliv/) & /bliv/ & /bəliv/ & salute \\
\hline
\end{tabular}

Note-An identical set of conditions existed for three-syllable words.

quency, and stress pattern to the experimental items. Nonwords were created by changing one or two phonemes. Experimental stimuli were counterbalanced across lists to include 12 trials in each condition and were rotated across lists to contain one version of the possible prime-target combinations (see Table 2). Prime and target stimuli were separated by $20 \mathrm{msec}$ of silence.

Two-syllable words. In addition to the 24 experimental items from Experiment 1, 66 fillers satisfying the same constraints outlined for the three-syllable words were selected (21 word-primeword-target pairs and 45 word-prime-nonword-target pairs). Of the filler words, seven words were produced in a first-syllable schwadeleted form and served as primes for nonword targets. Six stimuli lists were prepared, consisting of the 24 experimental and 66 filler items. Experimental stimuli were counterbalanced across lists so each participant heard the same number of stimuli (four) for each condition and were rotated across lists to contain one version of the prime/target combinations. Prime and target were separated by $20 \mathrm{msec}$ of silence.

\section{Procedure}

The participants were run either individually or in groups of 2 in a sound-dampened room. All the stimuli were presented binaurally over headphones (Sennheiser HD-250 II). The participants were instructed to indicate whether the second word they heard (the target) was a word or a nonword by pressing the appropriately labeled response key. Trials were separated by 1,500 msec. Responses were timed from the onset of the target stimulus. Each participant heard one of the two-syllable word lists and one of the three-syllable word lists. Presentation of the lists was counterbalanced across participants. List presentation was separated by a short break. The participants received a rest break after every 70 trials in the three-syllable list and after every 50 trials in the two-syllable list. Prior to each list, the participants responded to a short (16-item) practice session.

\section{Results}

Two- and three-syllable words were analyzed separately. Outliers (reaction times faster than $200 \mathrm{msec}$ or slower than 2,000 msec) were excluded from all analyses (fewer than $1 \%$ of the data). A significance level of $p<.05$ was adopted for all tests. Figures $1 \mathrm{~A}$ and $1 \mathrm{~B}$ show mean reaction time for three- and two-syllable words as a function of target (reduced and deleted) and prime type (repetition, variant, and control). Table 3 summarizes the priming effects for three- and two-syllable words.

Three-syllable words. A total of 11 participants' data sets were excluded from all analyses because they had an average percent correct of less than $66 \%$ or less than $50 \%$ in any one cell. One experimentalitem was excluded owing to experimenter error, as was the three-syllable item consistently misidentified in Experiment 1 . A 2 (target type) $\times$ 3 (prime type) ANOVA showed a main effect of prime type $\left[F_{1}(2,170)=352, M S_{\mathrm{e}}=6,587 ; F_{2}(2,138)=376\right.$, 
A Three-syllable words

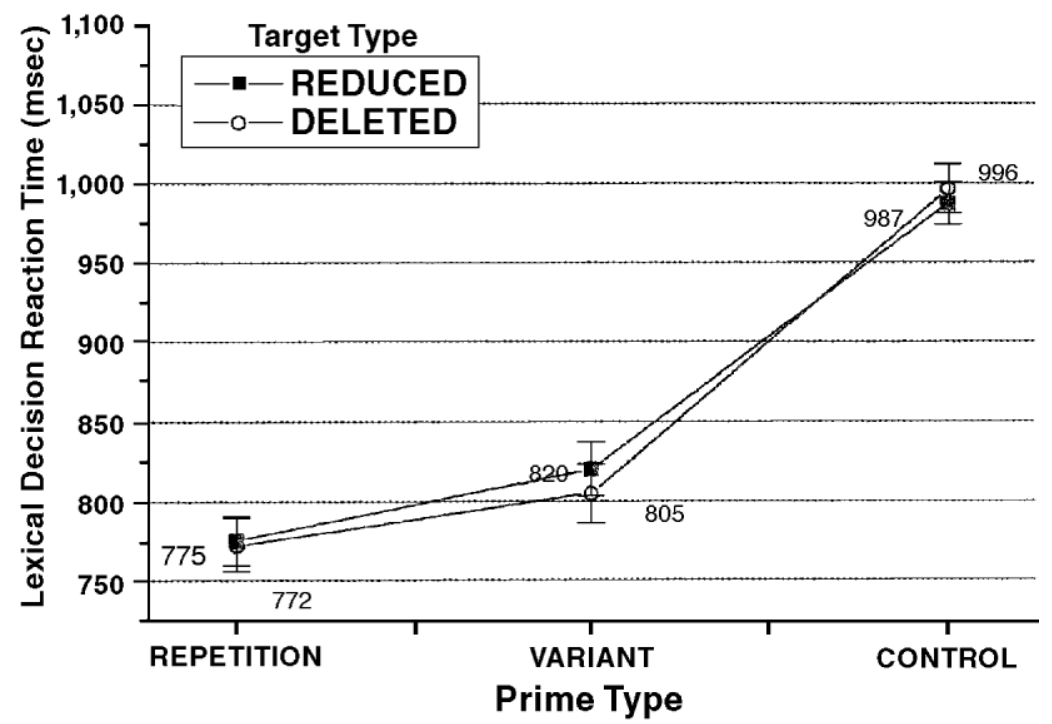

B Two-syllable words

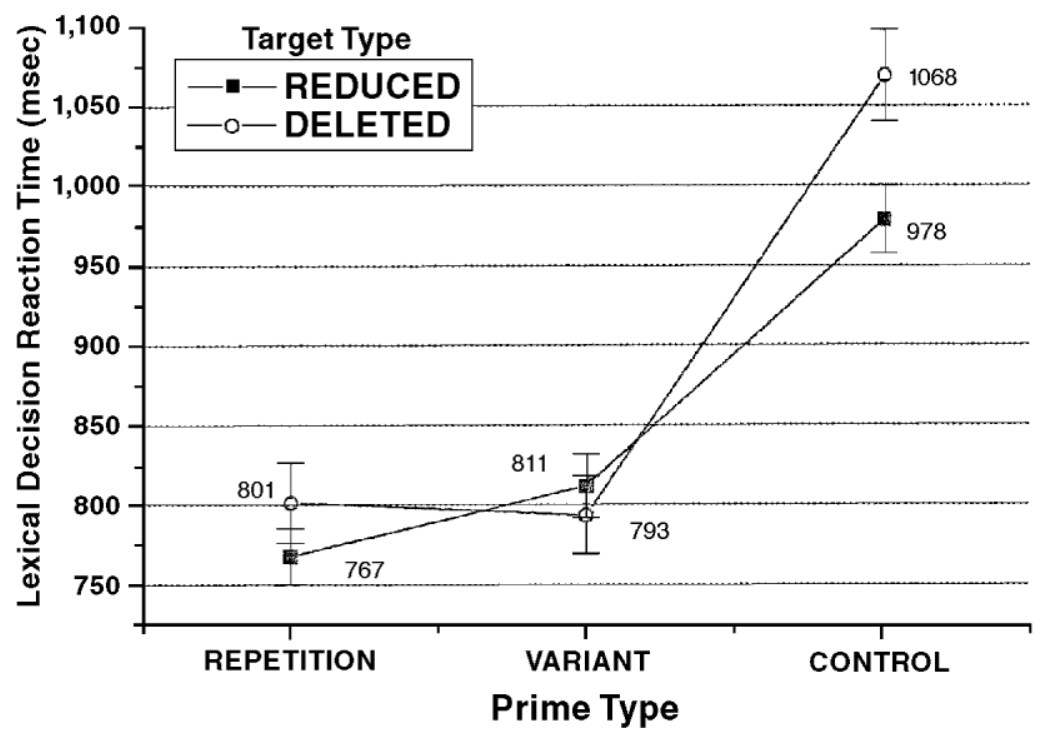

Figure 1. Experiment 2: Mean reaction time (in milliseconds) as a function of prime type (repetition, variant, and control) and target type (reduced and deleted). Error bars represent standard errors of the mean.

$\left.M S_{\mathrm{e}}=5,629\right]$. Overall, responses were faster in the repetition condition $(775 \mathrm{msec})$ than in the variant condition $\left[812 \mathrm{msec} ; F_{1}(1,85)=36.17, M S_{\mathrm{e}}=3,519 ; F_{2}(1,69)=\right.$ $\left.16.09 ; M S_{\mathrm{e}}=4,384\right]$ and the control condition [ $992 \mathrm{msec}$; $F_{1}(1,85)=574, M S \mathrm{e}=7,088 ; F_{2}(1,69)=589, M S_{\mathrm{e}}=$ $6,131]$. In turn, responses in the variant condition were faster than those in the control condition $\left[F_{1}(1,85)=301\right.$, $\left.M S_{\mathrm{e}}=9,157 ; F_{2}(1,69)=420, M S_{\mathrm{e}}=6,373\right]$. No other effects were significant.

Percentage correct is shown in Table 4. A comparable ANOVA performed on percentage correct showed a main effect of target type $\left[F_{1}(1,85)=50.22, M S_{\mathrm{e}}=128\right.$;
$\left.F_{2}(1,69)=22.82, M S_{\mathrm{e}}=263\right]$. Vowel-bearing targets $(95 \%)$ were responded to more accurately than vowel-deleted variants $(88 \%)$. There was also a main effect of prime type $\left[F_{1}(2,170)=10.74, M S_{\mathrm{e}}=128 ; F_{2}(2,138)=8.96, M S_{\mathrm{e}}=\right.$ 87]. Responses in both the repetition (93\%) and the variant $(92 \%)$ conditions were more accurate than those in the control condition (89\%). Accuracy did not differ between the repetition and the variant conditions.

Two-syllable words. A total of 25 participants' data were discarded from all analyses; 19 according to the same criteria described for the three-syllable words, 3 owing to technical problems, and 3 in order to counterbalance across 
Table 3

Difference Scores as a Function of Prime Type (Repetition, Variant, and Control), Target Type (Reduced and Deleted), and Stimulus Type (Two- and Three-Syllable Words) in Experiment 2

\begin{tabular}{cccccccc}
\hline & \multicolumn{3}{c}{ Three-Syllable Stimuli } & & \multicolumn{3}{c}{ Two-Syllable Stimuli } \\
\cline { 2 - 4 } \cline { 6 - 8 } Target & Con-Rep & Con-Var & Rep-Var & & Con-Rep & Con-Var & Rep-Var \\
\hline Reduced & 212 & 167 & -45 & & 211 & 167 & -44 \\
Deleted & 224 & 192 & -32 & & 267 & 275 & 8 \\
\hline
\end{tabular}

lists. In addition, the 4 two-syllable items consistently misidentified in Experiment 1 were excluded from all analyses. ${ }^{3}$

A 2 (target type) $\times 3$ (prime type) ANOVA was conducted and showed a main effect of target type $\left[F_{1}(1,71)=\right.$ $6.74, M S_{\mathrm{e}}=19,962 ; F_{2}(1,19)=4.36, M S_{\mathrm{e}}=11,595, p=$ $.0503]$. Reduced targets $(853 \mathrm{msec})$ were responded to faster than deleted targets $(888 \mathrm{msec})$. The main effect of prime type was also significant $\left[F_{1}(2,142)=126, M S_{\mathrm{e}}=\right.$ 20,$\left.276 ; F_{2}(2,38)=99.9, M S_{\mathrm{e}}=8,089\right]$. Responses in the repetition condition $(785 \mathrm{msec})$ and the variant prime condition $(803 \mathrm{msec})$ were faster than those in the control condition $(1,024 \mathrm{msec})$. The interaction between target type and prime type was significant by participants $\left[F_{1}(2,142)=\right.$ $\left.5.33, M S_{\mathrm{e}}=20,009\right]$ and was marginal across items $\left[F_{2}(2,38)=2.67, M S_{\mathrm{e}}=7,245, p=.08\right]$.

The asymmetry across reduced and deleted targets indicated by the interaction is made clear by the different patterns of priming effects. For reduced targets, there was a reduction in priming $(44 \mathrm{msec})$ when presented with the variant prime, as compared with the repetition prime $\left[t_{1}(71)=2.5, t_{2}(19)=2.53\right]$. In contrast, deleted targets showed comparable reaction times, given the repetition and the variant primes. This pattern is distinctly different from the three-syllable deleted targets, which showed a processing cost in the variant condition for both target types.

A comparable ANOVA performed on percentage correct showed a main effect of target type $\left[F_{1}(1,71)=53, M S_{\mathrm{e}}=\right.$ $297 ; F_{2}(1,19)=12.78, M S_{\mathrm{e}}=362$ ]. Vowel-bearing targets (94\%) were responded to more accurately than voweldeleted variants $(82 \%)$. There was also a main effect of prime type $\left[F_{1}(2,142)=14.4, M S_{\mathrm{e}}=238 ; F_{2}(2,38)=8.43\right.$, $\left.M S_{\mathrm{e}}=136\right]$. Accuracy was greater in the repetition (90\%) and variant $(91 \%)$ conditions than in the control conditions $(82 \%)$. No other effects were significant.

\section{Discussion}

If the representation of three-syllable words does not include vowel information or if a global inference mech- anism operates to restore missing information prelexically, processing across repetition and variant prime conditions should be equivalent. In contrast, both deleted and intact vowel targets showed a comparable cost in the variant priming condition. This suggests that lexical representations of three-syllable words contain the optional vowel.

For two-syllable reduced targets, variant primes resulted in slower reaction times, as compared with repetition primes. This is similar to the pattern of results observed for the threesyllable words above, suggesting representation of the vowel. For two-syllable deleted targets, however, responses to both repetition and variant primes did not differ.

The pattern of results observed for two-syllable deleted targets is consistent with the ability to use phonological knowledge when lexical activation based on segmental overlap is insufficient for recognition. When phonological knowledge is made available via preactivation (by repeating a vowel-deleted token or by a preceding vowel-intact counterpart), phonological knowledge serves the functional purpose of increasing the probability of recognition. Apparently, two-syllable vowel-deleted tokens, in the absence of prior activation, do not provide sufficient activation to make available knowledge concerning a possible missing vowel. Consider, for example, the vowel-deleted prime cases (i.e., plice-plice and plice-police). In both situations, the prime (plice) creates an environment in which phonological knowledge of a potential variant is available. Given the following target plice, processing benefits from phonological knowledge and provides a boost in lexical activation. In contrast, processing of the target police provides sufficient activation, with the result that processing is neither hindered nor facilitated by a vowel-deleted prime. In this case, the phonological knowledge is available and accessible but has no functional role for recognition, because the input is sufficient for recognition.

In contrast to two-syllable words, three-syllable words benefit from the additional segmental redundancy between input and representation. This redundancy, an aspect of lexical extent (see Connine, 1994) acts to ensure that the

Table 4

Mean Accuracy as a Function of Prime Type (Repetition, Variant, and Control), Target Type (Reduced and Deleted), and Stimulus Type (Three- and Two-Syllable Words) in Experiment 2

\begin{tabular}{|c|c|c|c|c|c|c|c|c|c|c|c|c|}
\hline \multirow[b]{3}{*}{ Target } & \multicolumn{6}{|c|}{ Three-Syllable Stimuli } & \multicolumn{6}{|c|}{ Two-Syllable Stimuli } \\
\hline & \multicolumn{2}{|c|}{ Repetition } & \multicolumn{2}{|c|}{ Variant } & \multicolumn{2}{|c|}{ Control } & \multicolumn{2}{|c|}{ Repetition } & \multicolumn{2}{|c|}{ Variant } & \multicolumn{2}{|c|}{ Control } \\
\hline & $M$ & $S E$ & $M$ & $S E$ & $M$ & $S E$ & $M$ & $S E$ & $M$ & $S E$ & $M$ & $\overline{S E}$ \\
\hline Reduced & 96 & 0.59 & 96 & 0.71 & 92 & 0.77 & 95 & 1.3 & 96 & 1.2 & 90 & 2.1 \\
\hline Deleted & 89 & 1.20 & 88 & 1.60 & 85 & 1.20 & 85 & 2.2 & 86 & 2.3 & 74 & 2.6 \\
\hline
\end{tabular}


stimulus will be recognized, given missing vowel information, and as a consequence renders no functional utility for use of phonological knowledge. This does not mean that the phonological knowledge that these variants occur is not available or accessed; rather, it is not necessary. Sufficient activation is achieved via goodness of fit and lexical extent. Thus, although a vowel-deleted token is a less effective source of activation, it is sufficient, in itself, for recognition.

\section{EXPERIMENT 3}

It is possible that the design of Experiment 2 encouraged the use of certain strategies. Specifically, Experiment 2 did not contain trials in which prime/target overlap led to no (nonword) responses. The absence of such trials could encourage a strategy in which any overlap between prime and target predicted a word response (Zwitserlood, 1996). This would lead to fast responses in the related (overlapping) conditions and slow responses in the unrelated (control) condition. This would predict identical performance in control conditions regardless of target type and/or fast responding regardless of prime type and word length. The data from Experiment 2 do not support either strategy. Nevertheless, Experiment 3 was designed to include the overlapping prime/nonword-target trials. Finally, two- and three-syllable stimuli were combined within an experimental list in order to determine whether blocking influenced the results of Experiment 2.

\section{Method}

\section{Participants}

A group of 73 undergraduates from Binghamton University participated in the experiment to fulfill a course requirement.

\section{Materials and Design}

The full sets of two-syllable and three-syllable experimental items and fillers from Experiment 2 were used. We constructed 356 new fillers were consisting of 133 word/word three-syllable and 45 word/word two-syllable filler trials, 85 word/nonword (nonoverlap) three-syllable and 29 word/nonword (nonoverlap) two-syllable filler trials, as well as 48 three-syllable and 16 two-syllable (word/nonword) fillers containing overlap between prime and nonword target.

The complete set of 712 trials was divided into two lists containing 356 trials each. Each list consisted of 36 three-syllable and 12 two-syllable experimental items and 308 filler trials and contained the same number of each prime/target combination for both two- and three-syllable words. The participants heard both lists in the same session, separated by a short rest period, and list presentation was counterbalanced across participants.

\section{Results}

Reaction times faster than $200 \mathrm{msec}$ or slower than $2,000 \mathrm{msec}$ were excluded from all analyses (fewer than $1 \%$ of the data). A total of 12 participants' data were excluded from all analyses owing to an overall percentage correct of less than 70\%. An additional participant's data were excluded to counterbalance across conditions. A significance level of $p<.05$ was adopted for all tests. Items excluded from the Experiment 2 analysis were disregarded in the following analyses, and 1 two-syllable item was excluded owing to extremely slow response times and poor accuracy. Figures $2 \mathrm{~A}$ and $2 \mathrm{~B}$ show the mean reaction times for three- and two-syllable words. Table 5 summarizes the priming effects for two- and three-syllable words.

A 2 (stimulus length) $\times 2$ (target type) $\times 3$ (prime type) ANOVA was conducted and showed a three-way interaction that was significant by participants $\left[F_{1}(2,118)=\right.$ $\left.5.07, M S_{\mathrm{e}}=13,853\right]$ and marginal by items $\left[F_{2}(2,176)=\right.$ $\left.2.58, M S_{\mathrm{e}}=9,911, p=.078\right]$. Given this interaction, a closer examination of the data was conducted for each stimulus length separately.

Three-syllable words. A 2 (target type) $\times 3$ (prime type) ANOVA showed a main effect of prime type $\left[F_{1}(2,118)=132, M S_{\mathrm{e}}=5,027 ; F_{2}(2,140)=85.69\right.$, $\left.M S_{\mathrm{e}}=9,322\right]$. Responses in the repetition condition $(876 \mathrm{msec})$ were faster than responses in the variant (930 msec) and control (1,024 msec) conditions. Responses in the variant prime condition were faster than those in the control condition. A comparable ANOVA performed on percentage correct showed a main effect of target type $\left[F_{1}(1,59)=72, M S_{\mathrm{e}}=102 ; F_{2}(1,70)=13.86\right.$, $\left.M S_{\mathrm{e}}=611\right]$. Vowel-bearing targets $(92 \%)$ were responded to more accurately than vowel-deleted variants $(83 \%)$. No other effects were significant.

Two-syllable words. A 2 (target type) $\times 3$ (prime type) ANOVA showed a main effect of target type $\left[F_{1}(1,59)=\right.$ $\left.4.7, M S_{\mathrm{e}}=20,105 ; F_{2}(1,18)=5.56, M S_{\mathrm{e}}=10,722\right]$. Reduced targets $(914 \mathrm{msec})$ were responded to faster than deleted targets (946 msec). The main effect of prime type was also significant $\left[F_{1}(2,118)=28.58, M S_{\mathrm{e}}=26,671\right.$; $\left.F_{2}(2,36)=20.54, M S_{\mathrm{e}}=14,970\right]$. Responses in the repetition condition $(857 \mathrm{msec})$ were faster than responses in the variant $(919 \mathrm{msec})$ and control $(1,015 \mathrm{msec})$ conditions. Responses were faster in the variant condition than in the control condition. In addition, the interaction between target and prime type was significant across participants $\left[F_{1}(2,118)=4.07, M S_{\mathrm{e}}=26,641\right]$ and was marginal

Table 5

Difference Scores as a Function of Prime Type (Repetition, Variant, and Control), Target Type (Reduced and Deleted), and Stimulus Type (Three- and Two-Syllable Words) in Experiment 3

\begin{tabular}{lccccccc}
\hline & \multicolumn{3}{c}{ Three-Syllable Stimuli } & & \multicolumn{3}{c}{ Two-Syllable Stimuli } \\
\cline { 2 - 4 } \cline { 6 - 8 } Target & Con-Rep & Con-Var & Rep-Var & & Con-Rep & Con-Var & Rep-Var \\
\hline Reduced & 139 & 91 & -48 & & 218 & 129 & -89 \\
Deleted & 156 & 96 & -60 & & 98 & 63 & -35 \\
\hline
\end{tabular}




\section{A Three-syllable words}

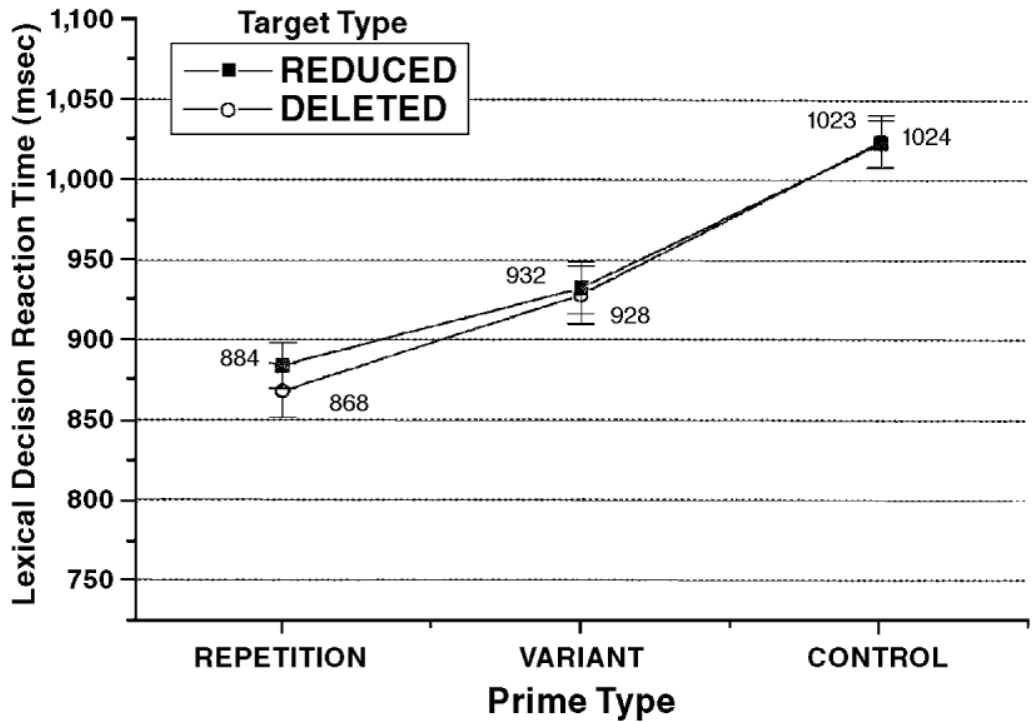

B Two-syllable words

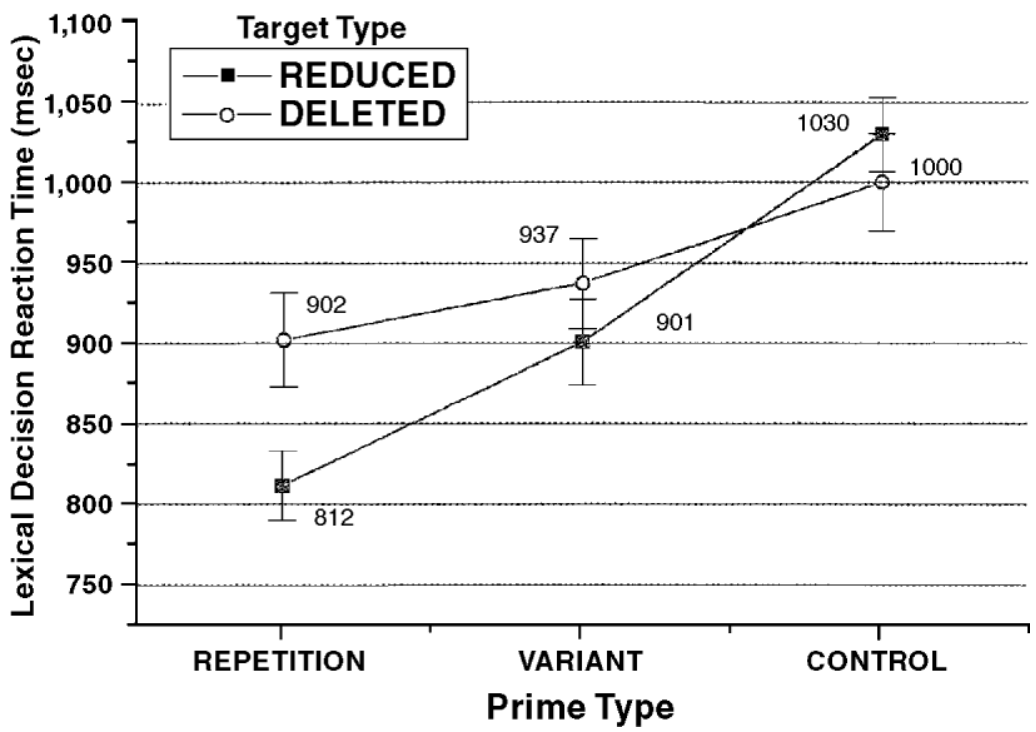

Figure 2. Experiment 3: Mean reaction time (in milliseconds) as a function of prime type (repetition, variant, and control) and target type (reduced and deleted). Error bars represent standard errors of the mean.

across items $\left[F_{2}(2,36)=2.0, M S_{\mathrm{e}}=11,894, p=.14\right]$. For two-syllable reduced targets, reaction times were slower in the vowel-deleted prime condition than in the repetition condition $\left[t_{1}(59)=3.22, t_{2}(18)=3.39\right]$. For two-syllable deleted targets, however, reaction times in the variant and repetition conditions did not differ. This is similar to the pattern of results observed in Experiment 2.

A comparable ANOVA performed on percentage correct (see Table 6) showed a main effect of target type $\left[F_{1}(1,59)=80.57, M S_{\mathrm{e}}=398 ; F_{2}(1,18)=16.25, M S_{\mathrm{e}}=\right.$ 643]. Vowel-bearing targets $(93 \%)$ were responded to more accurately than vowel-deleted variants $(74 \%)$. There was also a main effect of prime type $\left[F_{1}(2,118)=5.97\right.$, $\left.M S_{\mathrm{e}}=312\right]$ that was marginally significant across items $\left[F_{2}(2,36)=2.49, M S_{\mathrm{e}}=165, p=.09\right]$. Responses were more accurate in the repetition (85\%) and variant (86\%) conditions than in the control condition (79\%). Accuracy in the repetition and variant conditions did not differ.

\section{Discussion}

Similar to Experiment 2, two-syllable vowel-deleted stimuli showed comparable repetition and variant priming, 
Table 6

Mean Accuracy as a Function of Prime Type (Repetition, Variant, and Control), Target Type (Reduced and Deleted), and Stimulus Type (Three- and Two-Syllable Words) in Experiment 3

\begin{tabular}{|c|c|c|c|c|c|c|c|c|c|c|c|c|}
\hline \multirow[b]{3}{*}{ Target } & \multicolumn{6}{|c|}{ Three-Syllable Stimuli } & \multicolumn{6}{|c|}{ Two-Syllable Stimuli } \\
\hline & \multicolumn{2}{|c|}{ Repetition } & \multicolumn{2}{|c|}{ Variant } & \multicolumn{2}{|c|}{ Control } & \multicolumn{2}{|c|}{ Repetition } & \multicolumn{2}{|c|}{ Variant } & \multicolumn{2}{|c|}{ Control } \\
\hline & $M$ & $S E$ & $M$ & $S E$ & $M$ & $S E$ & $M$ & $S E$ & $M$ & $S E$ & $M$ & $S E$ \\
\hline Reduced & 92 & 1.09 & 93 & 1.08 & 89 & 1.04 & 92 & 2.09 & 93 & 1.94 & 93 & 1.82 \\
\hline Deleted & 83 & 1.43 & 81 & 1.89 & 83 & 1.69 & 78 & 3.00 & 78 & 3.11 & 64 & 2.97 \\
\hline
\end{tabular}

whereas vowel-reduced targets showed reduced variant priming. This pattern is consistent with the ability to use phonological knowledge when lexical activation based on segmental overlap is insufficient for recognition. Threesyllable targets showed a different pattern in which a reduction in priming in the variant condition occurred for both target types. These words benefitted from the additional segmental redundancy between input and representation and did not require utilization of phonological knowledge. The major difference between the two experiments was faster and more accurate responding in Experiment 2 . This is likely due to decreased stimulus variability in the blocked design.

\section{GENERAL DISCUSSION}

In three experiments, the effects of vowel deletion in spoken word recognition were investigated.Experiment 1 showed that vowel-deleted variants were rated as less acceptable than vowel-reduced variants, suggesting that the lexical representations include the schwa. In addition, the acceptability rating difference between the vowelreduced and the vowel-deleted variants was greater for two-syllable than for three-syllable words. Experiments 2 and 3 used form priming and found that two-syllable vowel-reduced targets showed larger priming for repetition conditions than for variant conditions. Vowel-deleted targets, however, showed comparable repetition and variant priming. In contrast, three-syllable targets showed reduced variant priming, relative to repetition priming. Experiment 3 replicated Experiment 2 with a mixed presentation design combined with the inclusion of overlapping prime/ nonword-target trials. These results support a number of interrelated conclusions.

The first claim concerns the lexical representation of words with possible vowel-deleted variants. The acceptability ratings and the phonological priming results converge on better acceptibility and enhanced recognition of the vowel-reduced variants. Both measures are consistent with a lexically represented schwa for both two- and threesyllable words. The combined results of the tasks suggest that pronunciation acceptability ratings may be used profitably to inform studies of phonological variation. Listeners were able to provide ratings that were accurately reflected in more traditional reaction time measures.

Given an assumption of explicit representation of the vowel, we argued that the processing of vowel-deleted variants involves activation on the basis of similarity that is augmented by knowledge of phonological variation. In our conceptualization, the use of available phonological knowledge boosts weak lexical activation-that is, in circumstances in which recognition based solely on stimulusto-representation matching might fail. The proposed account involves a relatively constrained use of phonological knowledge that precludes elaborated processing when unnecessary for recognition. As such, this is consistent with the lack of a phonological inference, given a variant that is homophonous with another word (cf. Gaskell \& MarslenWilson, 2001).

There are a number of advantages to such an account. First, this architecture capitalizes on a design characteristic of lexical activation-namely, that it is graded on the basis of similarity. The success a variant has in activating a lexical representation is dependent on the degree to which a unique lexical hypothesis is activated. As was suggested earlier, the amount of redundant information for two-syllable vowel-deleted tokens is not sufficient in itself to ensure recognition. The chance of recognition is limited not only by this lack of redundancy, but also by competition from similar sounding neighbors. The recruitment of phonological knowledge in such instances is beneficial, even necessary, for recognition. On the other hand, the greater redundancy in stimuli such as the three-syllable deleted variants helps ensure recognition, given missing information. In these cases, recruiting the use of phonological knowledge is unnecessary.

Second, this account prevents a broad-based utilization of phonological knowledge when it is inappropriate. This targeted use of phonological knowledge provides a boost for a weakly activated representation only when that lexical item has been previously experienced as a phonological variant. In the absence of prior knowledge concerning possible variant status, there are large numbers of words that are possible variants (e.g.; SPRING $\rightarrow$ *suPRING). Our conceptualization of the dependence of phonological inference on lexical activation prevents its inappropriate utilization in these situations.

A number of differences exist between the two- and the three-syllable words used here that may offer alternatives to the activation-based hypothesis described above. For both word lengths, the loss of vowel information results in both prosodic and syllabic restructuring, but the amount of information lost is proportionately greater for the two-syllable words. In addition, the site of vowel deletion occurs earlier for two-syllable words, resulting in greater constraint subsequent to the deletion site and, 
therefore, relatively later in processing, as compared with three-syllable words. Relatedly, three-syllable vowel deletions may be more acceptable because the deletion site is in a syllable that belongs to a foot headed by a preceding strong syllable. The deletion site for two-syllable words, on the other hand, occurs within a syllable that does not belong to a foot, but only to the prosodic word. It should be pointed out that the activation-based account and the alternatives suggested here are not mutually exclusive. It is possible that these descriptive differences have consequences in influencing a lexical item's activation level. These additional points highlight why the use of phonological knowledge is perhaps critical in processing twosyllable, but not three-syllable, schwa-deleted variants.

Yet another explanation has its basis in recent work in Dutch. Van Donselaar, Kuijpers, and Cutler (1999) found that recognition of variant words produced with an optional vowel (vowel epenthesis) was faster than the canonical, schwa-less, pronunciations. Van Donselaar et al. suggest that the inclusion of the schwa enhanced perceptibility of the cluster's initial consonant. This could accommodate the present finding that recognition of deleted tokens was more difficult. However, this explanation would have to be elaborated in order to accommodate the finding of comparable repetition and variant priming for two-syllable deleted targets.

Although the stimuli used had acceptable pronunciations in both forms (Kenyon \& Knott, 1951), corpus statistics indicate that vowel deletions may be less frequent for two-syllable than for three-syllable words. Dalby (1986) found that word-initial schwas in prestress environments (most similar to the two-syllable words used here) showed a deletion rate of $44 \%$, whereas word-medial, poststress schwas (most similar to the three-syllable words) showed a deletion rate of $62 \%$. For a slow speech tempo, deletion rates dropped to $2 \%$ and $13 \%$ for these environments. More recently, Patterson, LoCasto, and Connine (2001) examined a conversational database (Switchboard) and found a sixfold difference in deletion rate between two- and three-syllable words with identical structure to those used in the present experiments. Interestingly, the overall deletion rate for two-syllable words was very low (only 9.8\%), relative to three-syllable words $(54.7 \%)$. These corpus data highlight the weakly probabilistic patterning of schwa deletion for three-syllable words and its infrequent occurrence for two-syllable words. Both of these facts are consistent with an explicit representation of a potentially deleted schwa.

This patterning of variant productions is similar to that for unreleased stop consonants where only $59 \%$ of the stops are complete (Crystal \& House, 1988) and show systematicity based on voicing status (a release was less likely for voiced [18\%] than for voiceless [42\%] stops in wordfinal position). In a recent study, Deelman and Connine (2001) found that processing of segments in nonwords mirrored the corpus statistics in that voiced segments de- pended less on the release than did voiceless segments. Furthermore, the voicing asymmetry was modulated by the degree of lexical activation.

These findings are consistent with the present results in showing lexical involvement as a function of activation. Importantly, however, not all variants pattern in a weakly probabilistic fashion. Corpus statistics of frequency for American English medial flaps show that flapped productions are not simply a preferred but largely an exclusive production (/pridi/; Patterson \& Connine, 2001). The cognitive solution that has evolved for recognition of variants with these properties may not be via similarity and lexical knowledge, as is claimed here. Rather, lexical representations may evolve to directly reflect the surface rather than (or in addition to) the putative underlying representation.

Some recent research on processing vowel-deleted variants has shown results and conclusions that are seemingly at odds with the present experiments (Utman, Blumstein, \& Burton, 2000). In Utman et al., vowel deletions occurred in the initial unstressed syllable of multisyllabic words, and they found that vowel-deleted primes resulted in greater facilitation than did repetition primes. There are a number of differences across experiments that raise problems for direct comparisons. First, the materials used in these experiments combined two- and three-syllable words. The combined use of both material types renders their aggregated results a combination of two different processing patterns. Our results strongly support processing distinctions between these two word lengths. Second, voweldeleted stimuli were used as primes, but not as targets. This design offers no way to assess any asymmetric pattern as a function of target type. Third, a possible factor in the facilitation found with the vowel-deleted primes was that discrimination accuracy between the vowel-intact and the vowel-deleted versions was only $69 \%$. This suggests that the vowel-deleted versions may have contained some substantial vowel-present information.

Finally, Utman et al. (2000) concluded that the voweldeleted versions were the more frequent occurrence and, therefore, represented a closer fit to the structure of the lexical representation. Irrespective of the concerns outlined above, the relative frequency claim is counter to facts about the distribution of deleted variants. As was previously described, corpus analyses showed that vowel-deleted variants are encountered relatively infrequently (Patterson et al., 2001). Similarly inconsistent with the claim for voweldeleted representations were the results of Experiment 1, where vowel-intact stimuli were rated more highly acceptable and were identified more accurately.

Nevertheless, the present results, coupled with the Utman et al. (2000) data, raise a number of interesting questions. First, does the change in syllabic structure offer additional constraint to the processing of variants? Or is it simply the length or degree of lexical extent that drives these effects? Does the position of deletion have any ef- 
fect? We are currently investigating these alternatives in order to provide a clearer picture of how vowel-deleted variants are processed.

A final issue concerns the attribution of phonological priming effects to lexical versus prelexical levels of representation. Our account assumes that a strong lexical component is a factor in the comparable priming for the repetition and the variant priming conditions. This is particularly relevant for our interpretation of the repetition condition for two-syllable, vowel-deleted targets. It is possible, however, that a prelexical locus operating in the repetition condition could account for the comparable priming effects here. We do not deny a potential contribution from prelexical levels and note that there is evidence for a role of prelexical facilitation in phonological priming (Slowiaczek, McQueen, Soltano, \& Lynch, 2000). Our data do not permit us to rule out this account, but we offer a number of interrelated observations. A task analysis of another common task used in spoken language research, phoneme monitoring, has assumed that prelexical processing is generally less efficient than lexical processing (Cutler \& Norris, 1979; Norris, McQueen, \& Cutler, 2000). Thus, associating fast processing with prelexical processing is not a universal component of all tasks. More generally, repetition conditions have often been used as control conditions (see Zwitserlood, 1996, for a review of the priming paradigm), along with the implicit assumption that this condition will always produce the largest priming effects. As our and other recent data make clear, however, this is not always the case. We have discussed two of these studies above (i.e., Utman et al., 2000; van Donselaar et al., 1999). Since there is no longer a ubiquitous advantage to repetition cases per se, the current state of research simply does not permit a clear statement concerning the benefit of repetition, relative to other priming conditions. Clearly, additional research is required to place theoretical constraints on the locus of repetition priming effects.

Words that have undergone vowel deletion present a challenge to models of spoken word recognition that require strict alignment between the input and a lexical representation during word recognition. For example, Shortlist (Norris, 1994) incorporates a speech segmentation algorithm in which word onsets are hypothesized to occur at syllable onsets containing strong vowels (see Norris, McQueen, \& Cutler, 1995). If a deleted weak vowel in a two-syllable word is not inferred prelexically, the input representation will be misaligned relative to the target representation. We note, however, that characteristics of connected speech discourse (that parallel our variant priming conditions) may render the mismatch between a voweldeleted variant and its lexical representation functionally important for discourse processing. Fowler and Housum (1987) found that productions of old (previously said) words were reduced in duration and less intelligible than new words. However, the acoustic marker of old information was utilized to form a coherent discourse. Thus, paradoxically, an acoustic event that is potentially problematic from the point of view of spoken word processes may be exploited by discourse comprehension processes.

\section{REFERENCES}

Chomsky, N., \& Halle, M. (1968). Soundpatterns of English. New York: Harper \& Row.

Connine, C. M. (1994). Vertical and horizontal similarity in spoken word recognition. In C. Clifton, Jr., L. Frazier, \& K. Rayner (Eds.), Perspectives on sentence processing (pp. 107-120). Hillsdale, NJ: Erlbaum.

Connine, C. M., Blasko, D. G., \& Titone, D. (1993). Do the beginnings of spoken words have a special status in auditory word recognition? Journal of Memory \& Language, 32, 193-210.

Connine, C. M., \& Clifton, C., JR. (1987). Interactive use of lexical information in speech perception. Journal of Experimental Psychology: Human Perception \& Performance, 2, 291-299.

Connine, C. M., Mullennix, J., Shernoff, E., \& Yelen, J. (1990). Word familiarity and frequency in auditory and visual word recognition. Journal of Experimental Psychology: Learning, Memory, \& Cognition, 16, 1084-1096.

Connine, C. M., Titone, D., Deelman, T., \& Blasko, D. (1997).Similarity mapping in spoken word recognition. Journal of Memory \& Language, 37, 463-480.

Crystal, T. H., \& House, A. S. (1988). The duration of American-English stop consonants: An overview. Journal of Phonetics, 16, 285-294.

Cutler, A., \& Norris, D. (1979). Monitoring sentence comprehension. In W. E. Cooper \& E. C. T. Walker (Eds.), Sentence processing: Psycholinguistic studies presented to Merrill Garrett (pp. 113-134). Hillsdale, NJ: Erlbaum.

DAlby, J. (1986). Phonetic structure offast speech in American English. Bloomington: Indiana University Linguistics Club.

Deelman, T., \& Connine, C. M. (2001). Missing information in spoken word recognition: Non-released stop consonants. Journal of Experimental Psychology: Human Perception \& Performance, 27, 656-663.

Fear, B. D., Cutler, A., \& Butterfield, S. (1995). The strong/weak syllable distinction in English. Journal of the Acoustical Society of America, 97, 1893-1904.

Fowler, C., \& Housum, J. (1987). Talkers' signaling of "new" and "old" words in speech and listeners' perception and use of the distinction. Journal of Memory \& Language, 26, 489-504.

Gaskell, M. G., \& Marslen-Wilson, W. D. (1996). Phonological variation and inference in lexical access. Journal of Experimental Psychology: Human Perception \& Performance, 22, 144-158.

Gaskell, M. G., \& Marslen-Wilson, W. D. (1998). Mechanisms of phonological inference. Journal of Experimental Psychology: Human Perception \& Performance, 22, 380-396.

Gaskell, M. G., \& Marslen-Wilson, W. D. (2001). Lexical ambiguity resolution and spoken word recognition: Bridging the gap. Journal of Memory \& Language, 44, 325-349.

GERnSBACHER, M. A. (1984). Resolving 20 years of inconsistent interactions between lexical familiarity and orthography, concreteness and polysemy. Journal of Experimental Psychology: General, 113, 256-281.

Kenyon, J. S., \& KnotT, T. A. (1951). A pronouncing dictionary of American English. Boston, MA: Merriam.

McQueen, J., Norris, D., \& Cutler, A. (1994). Competition in spoken word recognition: Spotting words in other words. Journal of Experimental Psychology: Learning, Memory, \& Cognition, 20, 621-638.

NorRIS, D. (1994). SHORTLIST: A connectionist model of continuous speech recognition. Cognition, 52, 189-234.

Norris, D., McQueen, J. M., \& Cutler, A. (1995). Competition and segmentation in spoken-word recognition. Journal of Experimental Psychology: Learning, Memory, \& Cognition, 21, 1209-1228.

Norris, D., McQueen, J. M., \& Cutler, A. (2000). Merging information in speech recognition: Feedback is never necessary. Behavioral \& Brain Sciences, 23, 299-325.

Oshika, B., Zue, V. W., Weeks, R. W., Neu, H., \& Aurbach, J. (1975). The role of phonological rules in speech understanding research. IEEE Transactions on Acoustics, Speech, \& Signal Processing, ASSP-23, 104-112. 
Patterson, D., \& Connine, C. M. (2001). A corpus analysis of variant frequency in American English flap production. Phonetica, 58, 254-275.

Patterson, D., LoCasto, P. C., \& Connine, C. M. (2001). A corpus analysis of frequency of schwa deletion in conversational American English. Manuscript submitted for publication.

Slowiaczek, L. M., \& Hamburger, M. (1992). Prelexical facilitation and lexical interference in auditory word recognition. Journal of Experimental Psychology: Learning, Memory, \& Cognition, 18, 1239-1250.

SlowiaczeK, L. M., McQueen, J. M., Soltano, E., \& Lynch, M. (2000). Phonological representations in prelexical speech processing: Evidence from form-based priming. Journal of Memory \& Language, 43, 530-560.

Utman, J. A., Blumstein, S. E., \& Burton, M. W. (2000). Effects of subphonetic and syllable structure variation on word recognition. Perception \& Psychophysics, 62, 1297-1311.

van Donselaar, W., Kuijpers, C., \& Cutler, A. (1999). Facilitatory effects of vowel epenthesis on word processing in Dutch. Journal of Memory \& Language, 41, 59-77.

VAN OoIJEN, B. (1996). Vowel mutability and lexical selection in English: Evidence from a word reconstruction task. Memory \& Cognition, 24, 573-583.

Ye, Y., \& Connine, C. M. (1999). Processing vowels and lexical tone in Mandarin Chinese. Language \& Cognitive Processes, 14, 609630.

ZWIT SERLOOD, P. (1996). Form priming. Language \& Cognitive Processes, 11, 589-596.

\section{NOTES}

1. The distinction between strong and weak stress syllables has been made on the grounds of both vowel stress (see Chomsky \& Halle, 1968) and vowel quality. A vowel-stress-based definition holds that strong syllables are stressed syllables and weak syllables are unstressed syllables. A vowel quality definition, on the other hand, equates strong syllables with those containing full vowel quality and weak syllables with more midcentral (usually schwa) vowel quality (see Fear, Cutler, \& Butterfield, 1995 , for distinctions between the two definitions).

2 . The percentage of nonword responses was lower for vowel-reduced variants than for vowel-deleted variants for both three-syllable $(5.26 \%$ vs. $13.05 \%)$ and two-syllable words (5.12\% vs. $13.04 \%)$. This is consistent with the overall lower acceptability of the vowel-deleted variants.

3. An additional set of analyses was conducted for all the experiments that excluded the items where the deleted variant was phonotactically illegal. The pattern of results was consistent with the analyses reported here.

APPENDIX A

Three-Syllable-Word Set

\begin{tabular}{llll}
\hline symbolize & convolute & funeral & absolute \\
opera & factory & criminal & envelope \\
corporate & cabory & cardinal \\
mineral & dialogue & grocery & elephant \\
aspirin & gasoline & violet \\
bulletin & alkaloid & ambulance & homily \\
inference & mandolin & surgery & ovary \\
hickory & saccharine & hemorrhage & severance \\
beverage & vaporous & resolute & asterisk \\
bachelor & boisterous & insulin & general \\
devilish & family & accolade & history \\
monologue & national & mockery & average \\
mobilize & catholic & asteroid & regular \\
temporal & separate & broccoli & memory \\
avalanche & excellence & doctorate & dominant \\
boomerang & television & bribery & violence \\
numeral & salary & buffalo & definite \\
civilize & camera & & invalid \\
\hline
\end{tabular}

APPENDIX B

Two-Syllable-Word Set

\begin{tabular}{llll}
\hline suppose & police & parole & peruse \\
career & correct & pollute & morale \\
delight & parade & collide & corrupt \\
select & collect & saloon & balloon \\
collapse & bereave & believe & belong \\
canoe & beware & polite & careen \\
\hline
\end{tabular}

(Manuscript received April 17, 2000; 